\title{
A leitura coletiva teatral (dialogando com a escola)
}

\section{A theatrical collective reading (dialoguing with the school)}

Mei Hua Soares *

Resumo: Abordar aspectos da leitura coletiva realizada por jovens em dois grupos teatrais paulistanos para pensar as leituras realizadas na escola é o intuito do presente artigo. O treino do olhar e da escuta, o par ação-recepção, o caráter teleológico e o tempo da leitura são os elementos sobre os quais pretendemos nos debruçar. O estudo enfoca o leitor em diálogo com as práticas teatrais e escolares de leitura e tem como aporte teórico concepções de Wolfgang Iser e Hans Robert Jauss, da Estética da Recepção.

Palavras-chave: leitura coletiva, teatro, escola, jovem.

Abstract: Addressing aspects of collective reading by young in two theater groups (of São Paulo) to think the readings performed in school is the intention of this article. The practice of looking and listening, the couple action-reception, the teleological character and the reading time are the elements on which we intend to address us. The study focuses on the reader in dialogue with the theatrical and school practices of reading and its theoretical contribution conceptions of Wolfgang Iser and Hans Robert Jauss, of Aesthetic Reception.

Keywords: collective reading, theater, school, young.

\footnotetext{
* Doutora na área de Linguagem e Educação pela Faculdade de Educação da Universidade de São Paulo.
} 


\section{ntrodução}

Marcel Proust (2011), no texto "Sobre a leitura" - prefácio à tradução da obra Sésame et les Lys, de John Ruskin, publicada em 1907 - discorre sobre os prazeres solitários advindos da leitura silenciosa, sobre a amizade "primitiva" que se estabelece entre homens e livros; alerta sobre os perigos da erudição e da evasão via leitura e esboça literariamente ao seu leitor uma de suas muitas dimensões. O valor simbólico da leitura talvez pudesse ser ilustrado por intermédio de personagens literários, como Dom Quixote, criador de uma realidade própria fundamentada na ilusão (por sua vez proveniente da leitura). O "cavaleiro da triste figura", em determinado momento da trama, discorre sobre a importância atribuída à capacidade de leitura: "(...) que mal fica aos governadores não saberem ler nem escrever, porque o não saber um homem ler indica uma de duas coisas: ou que teve nascimento humilde e baixo, ou que foi tão travesso e tão mau, que não lhe pôde entrar na cabeça o bom costume nem a boa doutrina" (Cervantes, 1981 [1605]: 481).

$\mathrm{O}$ artigo que desenvolvemos aqui busca estabelecer pontos de contato entre a leitura de literatura, o teatro e a escola. Partindo da premissa que a leitura consiste em elemento fundamental à formação humana e um direito, na medida em que supre a necessidade de fabulação (Candido, 2013 [1988]), nosso intento é refletir sobre as leituras coletivas realizadas em grupos de teatro e pensá-las enquanto dispositivos que poderiam alimentar leituras coletivas escolares.

Logo de início, ao abordarmos o assunto, deparamo-nos com a difícil tarefa de aproximar a escola da literatura, do teatro e das artes. Como tratar metodológica e didaticamente elementos subjetivos neles engendrados sem que se perca de vista a dimensão do sensível? Como proporcionar um ambiente favorável à leitura coletiva (por vezes, as primeiras) junto a jovens adolescentes? Como tornar a leitura feita na escola mais atraente, mais significativa?

Pesquisando e observando práticas teatrais de leitura junto a grupos paulistanos de teatro ${ }^{1}$, cujos processos envolvem aspectos pedagógicos voltados ao jovem, tornou-se perceptível o quão potentes podem se revelar as leituras rea-

\footnotetext{
1 O artigo originou-se de tese de doutorado sobre práticas teatrais de leitura. Foram acompanhados durante a pesquisa os processos de leitura e criação da Cia. Antropofágica (PY) e Cia. Paidéia (Cia. Paidéia Jovem), ambas subsidiadas pelo Programa Municipal de Fomento para a cidade de São Paulo.
} 
lizadas coletivamente. Mediante registros, relatórios e entrevistas com diretores e artistas, foi possível detectar aspectos que subsidiam, portanto, o presente artigo. $\mathrm{O}$ contexto teatral fornece outras bases para a realização das leituras, $\mathrm{O}$ que pode se mostrar bastante frutífero para alimentar as leituras coletivas no contexto escolar.

Concomitantemente às investigações sobre como os artistas de teatro desenvolvem suas leituras - individual e coletivamente - e que valor a elas atribuem, também foram testadas estratégias de leitura em práticas coletivas junto a alunos de ensino médio da rede pública do estado de São Paulo, o que possivelmente fará parte de um estudo posterior.

A dificuldade em abordar o objeto de nosso olhar, a leitura, talvez se dê também pela enorme quantidade de textos e de menções que a ela se referem, o que amplia a nossa gama de interpretações, concepções e reflexões, mas também condiciona a nossa visão. Ao longo dos tempos, poetas, historiadores, sociólogos e filósofos discorreram sobre a leitura, o leitor, o livro, a obra literária. No campo da educação, o enfoque dado à leitura se expande para questões relacionadas ao letramento, à formação de alunos e professores, à proficiência leitora, ao ensino de literatura, às imbricações entre leitura e escrita entre outros aspectos. Se pensarmos, por exemplo, na representação de leitura de Marcel Proust, verificaremos que ele se reporta especificamente às leituras silenciosas, solitárias, o que certamente determina especificidades inerentes a esse tipo de prática leitora. No entanto, para nossa pesquisa, o interesse se volta para as leituras realizadas coletivamente. Quais as possíveis "perdas e ganhos" se cotejarmos ambas (leitura silenciosa e leitura coletiva)? Ou melhor, que diferentes contornos a leitura coletiva pode imprimir no percurso do leitor?

O nosso principal referencial teórico na abordagem sobre leitura consiste nos textos de autores da Estética da Recepção, originária da Escola de Constança, na década de 1970. O enfoque dado por Hans Robert Jauss e Wolfgang Iser localiza o leitor como peça-chave para o entendimento da leitura e da fruição estética. Segundo Terry Eagleton, poderíamos "periodizar a história da moderna teoria 
literária em três fases" ${ }^{2}$. Privilegiar o enfoque no leitor poderá aclarar aspectos referentes às leituras feitas individual ou coletivamente.

\section{Ler na escola e no teatro}

Deslocar o foco da metaleitura para a leitura literária, sair da análise do texto e ir em direção ao leitor é uma possibilidade para a escola que tem sido aventada ultimamente, desde a inserção, nos estudos sobre literatura e ensino, das discussões sobre Estética da Recepção. Ora, para tudo o que se faz com a literatura na escola, é preciso que ela seja lida; a obra não existe sem o leitor, e a escola só conseguirá ter esse leitor se ele for capaz de alguma fruição na leitura, do contrário o aluno resistirá a ela. Segundo Stanley Fish, o leitor está sempre interpretando com base num repertório e num modo de perceber que foi em parte estruturado pelo meio em que foi formado, ao que denomina de "comunidade interpretativa". Para ele, a leitura pode ser intersubjetiva e, desse modo, compartilhada (Fish, 1980: 342). Pensando nestas bases, as leituras realizadas pelos integrantes de um grupo de teatro poderiam ser consideradas como pertencentes a uma "comunidade interpretativa", uma vez que estão imersos em um conjunto mais amplo de perspectivas culturais, artísticas e políticas. A escolha das leituras realizadas conjuntamente, por exemplo, não são aleatórias. São fruto dos anseios, das necessidades e das perspectivas de um grupo específico. Nesse caso, as leituras, bem como a sua recepção ou apropriação, serão estruturadas a partir da chave que rege outras demandas ou ações do grupo. A formação de leitura decorrente das leituras coletivas realizadas no interior dos grupos inevitavelmente sofrerá influências das orientações que sustenta esse mesmo grupo. O que não impossibilita, no entanto, a coexistência de uma dimensão individual de recepção aliada a essa "interpretação coletiva" durante a leitura dos textos e nos diálogos a ela subsequentes. Essa movimentação proveniente da alternância

\footnotetext{
2 “(...) uma preocupação com o autor (romantismo e século XIX); uma preocupação exclusiva com o texto (Nova Crítica) e uma acentuada transferência da atenção para o leitor, nos últimos anos. O leitor sempre foi o menos privilegiado desse trio - estranhamente, já que sem ele não haveria textos literários. Estes textos não existem nas prateleiras das estantes: são processos de significação que só se materializam na prática da leitura. Para que a literatura aconteça, o leitor é tão vital quanto o autor". (EAGLETON,2006: 113)
} 
entre o repertório particular dos envolvidos e as concepções coletivas assemeIha-se a outro tipo de movimentação que está imbricado no processo de leitura. Michel Picard (apud Jouve, 2002) ao propor estudar a recepção literária sob a perspectiva do jogo, aponta duas categorias distintas [o "playing" e o "game"] norteadoras da leitura que nos remetem a essa ambivalência do ato leitor. Vincent Jouve esclarece a questão:

O playing é um termo genérico para todos os jogos de representação ou simulacro, fundamentados na identificação com uma figura imaginária. O game, por sua vez, remete aos jogos de tipo reflexivo, precisando de saber, inteligência e sentido estratégico. (...) Enquanto o estatuto objetivo do game permite o distanciamento, o playing enraíza-se no imaginário do sujeito. A leitura seria portanto, ao mesmo tempo, jogo de representação e jogo de regras. É impossível ler um romance sem se identificar com tal personagem. Mas é igualmente impossível não respeitar um certo número de convenções, códigos e contratos de leitura. (Jouve, 2002: 111112)

Vincent Jouve, ao sintetizar as ideias dos teóricos da recepção, apresenta ainda três instâncias do leitor identificadas por Michel Picard, em A leitura como jogo (1986), o "ledor", o "lido" e o "leitante":

O "ledor" é definido como a parte do indivíduo que, segurando o livro nas mãos, mantém contato com o mundo exterior; o "lido", como o inconsciente do leitor que reage às estruturas fantasmáticas do texto; e o "leitante", como a instância da secundaridade crítica que se interessa pela complexidade da obra. (Jouve, 2002: 50)

Se pensarmos na leitura realizada pelos jovens atores e atrizes dos grupos de teatro em questão, verificaremos, por exemplo, que essas instâncias leitoras e as disposições que envolvem a prática cênica são constantemente mobilizadas. Há uma parte racional, relacionada à operação e domínio das regras do jogo de leitura - nesse caso, a coletiva - e outra mais subjetiva, relacionada a como as leituras operam no interior do indivíduo, em seu imaginário, as reverberações.

Talvez haja semelhança entre os dispositivos de funcionamento próprios da atuação e as instâncias referentes à recepção leitora, enumeradas por Picard. 0 
artista-ator, ao lidar com a leitura, lida também com a criação cênica. Ao desenvolver o estudo de um papel, a elaboração de uma personagem, a criação de uma peça, também desdobra a sua ação em diferentes instâncias. Algumas se referem à materialização da criação e ao diálogo com o mundo exterior (circulação pelo espaço, marcas, elementos de cena, figurinos, falas, contato e consciência da plateia etc.); outras estão relacionadas ao preenchimento "humano" exigido pela construção das personagens, ou seja, à mobilização de diferentes emoções, sentimentos, sentidos para a efetivação da criação cênica, geralmente despertados pela situação ou contexto ficcional envolvido na peça; e há ainda as instâncias de cunho crítico-reflexivo que, em geral, antecedem e dão suporte para a compreensão e posicionamento frente à totalidade da obra que se está encenando. A aproximação dessas instâncias, que circundam tanto o ato leitor quanto o cênico, e o fato de serem exigidas constantemente dos jovens artistas envolvidos nos grupos teatrais aponta para um traço distintivo no trato com a leitura. Esse treino via provocação das instâncias mencionadas possibilita maior "traquejo" na transposição e na apropriação, o que decorre da familiaridade com tais processos, tanto na leitura quanto na atuação.

Outro aspecto relevante com relação à maior intimidade com a leitura por parte dos jovens artistas-atores está relacionado ao par ação-recepção, que aguça a fruição e é constantemente solicitado ao longo das improvisações e cenas. Durante os ensaios, aqueles que agora escutam, no momento seguinte estão lendo; os que estão assistindo à encenação dos colegas, logo estarão encenando também. Isso provoca uma predisposição dinâmica tanto à ação quanto à recepção. Ambos são importantes e ambos são valorizados.

Olhar, perceber, fruir e refletir sobre as cenas dos pares é algo que também influi na relação com a leitura. Como um treino para diferentes recepções. 0 acesso a um leque mais amplo de possibilidades interpretativas, fruições estéticas ou recepções, tanto no âmbito literário quanto no teatral, é o que garante a substancialidade formativa do jovem sujeito leitor-ator. Não se trata somente do acesso, conforme mencionado, mas principalmente da apropriação dos diferentes modos de ler ou de atuar; modos que o indivíduo (leitor ou ator) não dominava e passa a dominar, ou seja, as habilidades que desenvolvem não só a sua capacidade leitora, mas também as que constituem a sua inserção em um campo de forças (Bourdieu, 1990) - literário, teatral, educacional - ao qual, em princípio, não pertencia. 
Mas transitar com propriedade pelas instâncias mencionadas, tanto durante a leitura quanto a atuação cênica, não consiste em tarefa simples. Pode-se ainda não estar preparado para a recepção de obras com as quais não se estabelece uma relação imediata de identificação, por exemplo. 0 estranhamento causado por uma obra pela qual um jovem leitor não vê despertado o seu interesse, talvez não o impulsione, na maior parte das vezes, a obter um distanciamento crítico, fato mais facilmente observável em leitores mais desenvoltos - com outras referências literárias - ou mais adultos. Essa questão, longe de querer ser determinista, aponta apenas uma necessidade de ampliar não somente o horizonte de leitura do jovem leitor, mas também as suas experiências sociais, culturais, de vida.

A transição de um determinado tipo de leitor (diretamente envolvido com texto) para outro (distanciado, crítico), por exemplo, apresenta dificuldade em se efetuar possivelmente pelo fato da leitura identificada propiciar um efeito catártico poderoso. O receptor, ao ser "lido" pela obra, entrevê a si mesmo. É fundamental considerar que esses tipos de leitores convivem, ou não, no mesmo leitor; não são pessoas diferentes, mas diferentes níveis de leitura. O leitor, na estrita definição do termo, ou seja, "aquele que lê", e lê autonomamente, escolhe e maneja a leitura segundo suas próprias regras.

Um leitor proficiente na arte de ler poderia, por exemplo, escolher entre a leitura de um best-seller ou uma obra canônica, entre o consumo de um produto cultural ou uma obra de arte complexa. Mas o poder de escolha - e a capacidade de ser receptor das mais diferentes formas literárias e estéticas - é o que determina a sua autonomia leitora. Como alcançar essa "proficiência leitora" seria o ponto determinante a ser investigado. Nosso estudo aponta que nas leituras e nos processos de pesquisa teatral dos grupos de teatro observados residem elementos-chaves para se pensar na aquisição dessa capacidade de leitura mais potente. $\mathrm{O}$ fato dos grupos teatrais agregarem integrantes de diferentes faixas etárias, por exemplo, enriquece o processo, na medida em que os mais jovens têm acesso a diferentes olhares interpretativos, ao passo que os mais velhos podem ter contato com as recepções mais isentas de juízos críticos (ver com "olhos livres"). E essa troca é contínua, uma vez que as rodas de compartilhamento em que acontecem as leituras coletivas fazem parte do funcionamento do grupo, seu modus operandi. 
Hans Robert Jauss apresenta três experiências fundamentais do prazer estético decorrentes da leitura: uma referente à criação (poiesis) artística ou à possibilidade "segundo a qual, o indivíduo, pela criação artística, pode satisfazer a sua necessidade geral de 'sentir-se em casa no mundo' ao 'retirar do mundo a sua dura estranheza' e convertê-la em sua própria obra"; outra estaria relacionada à "percepção reconhecedora" e ao "reconhecimento perceptivo" (aisthesis), ou seja, à recepção sensível ; e, por último, aquela responsável pelo caráter comunicativo da experiência estética, "capaz de conduzir o ouvinte e o espectador tanto à transformação de suas convicções quanto à liberação de sua psique" (katharsis) (Jauss, 2002: 101), que poderíamos aproximar tanto da identificação quanto do distanciamento crítico, das reverberações que uma obra ocasiona no sujeito. Esta última estaria relacionada ainda, segundo o autor, a uma função social da arte enquanto mediadora, inauguradora e legitimadora de normas de ação.

Considerando esses três aspectos engendrados no processo leitor, poderíamos utilizá-los para pensar a leitura envolvida nas práticas teatrais. $\mathrm{O}$ ator age. Sua leitura, dentro do teatro, está intimamente ligada à ação. Mesmo quando as leituras são teóricas e tem por finalidade fornecer embasamento informativo a respeito de tal e qual assunto, ainda assim, o artista teatral não perde de vista a sua postura atuante. Ao agir, ele cria. Atende aos anseios da criação (poiesis). $\mathrm{O}$ ator é também espectador. A sala de ensaio é o lugar em que mais se assiste. Portanto, ele está imerso na recepção de leituras e de cenas (aisthesis) e com elas trava diálogo constante. E esse diálogo, consciente ou inconscientemente traduz-se em novas apropriações. O que ele faz, o que ele vê e ouve reverbera nele e nas cenas e personagens que ele cria. Nesse sentido, se as leituras silenciosas e solitárias dificilmente possibilitam acesso aos ecos deixados no sujeito leitor, as leituras teatrais (coletivas e individuais) podem revelar pistas do que cada obra ou leitura proporcionou. Há pistas sobre as impressões de leitura, e pistas já digeridas e transformadas. São apenas indícios, mas para quem lida com formação de leitura e com elementos tão subjetivos, é uma espécie de devolutiva da leitura, algo que possibilita redirecionar a escolha dos textos, a seleção de gêneros, de temas e de estratégias metodológicas.

Outro aspecto a ser considerado nas leituras realizadas nos grupos teatrais é o caráter teleológico da leitura, ou seja, há uma finalidade primeira no tocante às leituras teatrais: lê-se para criar, para encenar. A leitura com vistas à ação 
e criação cênica adquire, desse modo, por intermédio do cultivo de um comportamento estético propenso a experimentações, um valor específico dentro das práticas de teatro. $\mathrm{E}$, paralelamente, as práticas de teatro imprimem à leitura uma força de ação que impulsiona a criação e retira a passividade - física ou "civilizada" - geralmente a ela associada ou atribuída. Nem todas as leituras proporcionarão elementos para a cena ou personagem que se está trabalhando no momento. Os textos são de diferentes gêneros (ensaios, crônicas, contos, romances, reportagens, manifestos, entrevistas etc.) e nem sempre atendem às necessidades emergenciais dos improvisos e encenações dos atores e atrizes instantaneamente. Mas eles são um grupo, portanto, nas próximas encenações, nos próximos projetos, permanecerão os mesmos integrantes. As leituras, então, acabam encerrando um repertório comum, algo que pode e será acionado sempre que necessário nos processos subsequentes. Cria-se um círculo de leitura e de leitores que partilham praticamente dos mesmos referenciais, uma comunidade leitora.

As leituras feitas em voz alta, por sua vez, apresentam traços peculiares. 0 romancista e ensaísta Alberto Manguel narra um episódio curioso envolvendo a leitura feita em voz alta por ele para o escritor Jorge Luis Borges. Após breve encontro numa livraria, Borges solicita seus préstimos de leitor, pois estava ficando cego. Manguel, então, se torna um "veículo de leitura" para Borges:•

Nos dois anos seguintes, li para Borges, tal como o fizeram muitos outros conhecidos afortunados e casuais, à noite ou, quando a escola permitia, pela manhã. O ritual era sempre o mesmo. Ignorando o elevador, eu subia pelas escadas até o apartamento (...). Não havia preliminares: enquanto eu me acomodava na poltrona, ele sentava ansioso no sofá, e com uma voz levemente asmática, sugeria a leitura daquela noite. "Deveríamos escolher Kipling hoje? Hein?" (...) Eu não lera muitos desses autores antes, e assim o ritual era curioso. Eu descobria um texto lendo-o em voz alta, enquanto Borges usava seus ouvidos como outros leitores usam os olhos, para esquadrinhar a página em busca de uma palavra, de uma frase, de um parágrafo que confirme alguma lembrança. Enquanto eu lia, ele interrompia, fazendo comentários sobre o texto a fim de (suponho) tomar notas em sua mente. (Manguel, 1997: 30-31) 
O "ritual de leitura" descrito apresenta implicações da modalidade oral tanto para Borges (ouvinte) quanto para Manguel (o leitor que profere as palavras), cada um a sua maneira, a partir da mesma leitura. Interessantes também são os comentários feitos por Borges ao longo da leitura, o que segundo Manguel consistia em elemento de perlaboração acoplado à leitura oralizada e em acesso às impressões do outro por parte do jovem leitor:

Jamais tive a sensação de apenas cumprir um dever durante minhas leituras para Borges; ao contrário, era como se fosse uma espécie de cativeiro feliz. Eu ficava fascinado não tanto pelos textos que me fazia descobrir (...), mas por seus comentários, nos quais havia uma erudição imensa, mas discreta, e que podiam ser muito engraçados, às vezes cruéis, quase sempre indispensáveis. (...) ler em voz alta para ele aqueles textos que eu já lera antes modificava aquelas leituras solitárias anteriores, alargava e inundava minha lembrança dos textos, fazia-me perceber o que não percebera então, mas que agora parecia recordar, sob o impulso da reação dele. (Manguel, 1997: 33-34)

Por fim, ele arremata, "aprendi rapidamente que ler é cumulativo e avança em progressão geométrica: cada leitura nova baseia-se no que o leitor leu antes" (MANGUEL, 1997: 33), confirmando a intertextualidade que percorre as leituras que realizamos, recuperando sentidos, modificando conceitos, perpassando nossos referenciais literários e existenciais, e a construção de um repertório de leituras. O mesmo Alberto Manguel reserva um dos capítulos de seu livro para abordar a leitura ouvida; a discorrer sobre a inovação nas práticas de leitura do século XIX ${ }^{3}$, descreve a decisão tomada pelo poeta Saturnino Martínez e alguns intelectuais cubanos que, juntos, passaram a publicar um jornal, $L a$ Aurora, - composto por notícias políticas, poemas e contos - para trabalhadores da indústria de charutos. No entanto, observaram que o analfabetismo era um impeditivo para o acesso à leitura por parte de muitos trabalhadores. A solução

\footnotetext{
3 Na verdade, uma retomada do modo de ler da Idade Média: "Reunir-se para ouvir alguém ler tornou-se também uma prática necessária e comum no mundo laico da Idade Média. Até a invenção da imprensa, a alfabetização era rara e os livros, propriedade dos ricos, privilégio de um pequeno punhado de leitores. (...) as pessoas que queriam familiarizar-se com determinado livro ou autor tinham amiúde mais chance de ouvir o texto recitado ou lido em voz alta do que de segurar o precioso volume me mãos" (Manguel, 1997: 138).
} 
foi a realização de leituras públicas do jornal: um operário lector passou a ler as notícias que, em pouco tempo, ganharam a reputação de subversivas (Manguel, 1997). Outras iniciativas semelhantes são descritas por ele, como essa em que Mario Sánchez, pintor (cujo pai fora um lector), lembra das impressões deixadas pelo lector, que, neste caso, lia romances chegando a interpretar personagens e a modular vozes, o que causava impacto na recepção dos demais operários:

Os operários que haviam trabalhado muitos anos nas fábricas eram capazes de citar de memória longos trechos de poesia e mesmo de prosa. (...) Ouvir alguém lendo para eles, descobriram os charuteiros, permitia-Ihes revestir a atividade de enrolar as folhas escuras do tabaco - atividade mecânica e entorpecedora da mente - com aventuras a seguir, ideias a levar em consideração, reflexões das quais se apropriar. Não sabemos se, durante as longas horas na fábrica, lamentavam que o resto de seus corpos não participasse do ritual de leitura; não sabemos se os dedos daqueles que sabiam ler ansiavam por virar uma página, por seguir uma linha; não sabemos se aqueles que nunca haviam aprendido a ler eram estimulados a fazê-lo. (MANGUEL, 1997: 136)

A leitura e a escuta coletiva acontecem ao longo das práticas a que nos propusemos observar. Ambas exigem atenção e treino. A leitura coletiva em voz alta só funcionará mediante a instauração de uma prática constante, cultural, fomentada pelos envolvidos, demandada por eles. Paul Zumthor também se reportará à leitura em voz alta, mas enfatizando o seu caráter performático, o empenho do corpo, os impactos na recepção (Zumthor, 2007).

A leitura pública, realizada coletivamente e em voz alta, sofreu transformações ao longo dos tempos. Uma delas está relacionada ao desinteresse pelas leituras proveniente, em grande medida, pelo avanço das tecnologias, do privilégio da imagem, do ritmo de comunicação pautado pela rapidez, todos traços contemporâneos que, juntos, parecem desenhar um panorama em primeira instância negativo ${ }^{4}$ à propagação do tipo de leitura que abordamos. Ainda assim,

\footnotetext{
4 Informações coletadas em relatórios, registros de atividades e entrevistas durante a pesquisa de campo trouxeram material de análise que sustentou a elaboração de tese de doutorado sobre práticas teatrais de leitura. Com relação ao esvaziamento de público para as leituras orais, ele foi mencionado na entrevista com um dos diretores (Thiago Reis Vasconcelos) dos grupos pesquisados - Cia. Antropofágica - quando este descrevia as atividades do início da companhia:
} 
consideramos essa modalidade de prática leitora essencialmente rica, especialmente para se pensar em processos criativos ou formativos envolvendo grupos de indivíduos, como é o caso dos grupos de teatro e das turmas escolares.

\section{Tempo da leitura}

E quanto ao tempo? O tempo da leitura literária, ou da formação de leitura, é seguramente outro que não o do ritmo cotidiano. Para que o leitor leia sentidos nas palavras do texto, para que transite por signos verbais e Ihes atribua significados, para que consiga explorar cuidadosamente as entrelinhas, de modo a compreender seu emaranhado, "descobrindo prazer no simples som das palavras ou nas pistas que as palavras não queriam revelar" (Manguel, 1997: 27), defendemos aqui que a leitura necessita de tempo. Tempo para e tempo de: ficção, poesia, alumbramento, elaboração e reelaboração das coisas lidas e ouvidas. E esse tempo, ponto fundamental para o fôlego que exige a leitura literária, inexiste na esfera escolar. A maturação dos termos, dos conceitos, sua conexão com outras, o estilo, o contexto, a intertextualidade leva tempo. Um tempo de uma vida. Mesmo as leituras fulcrais, que realizamos em determinado período, sofrem mutações ao longo das releituras, por exemplo. E esse tempo, que a escola talvez não possa fornecer in locu, é exigência da leitura de literatura. Se a escola, dada a sua estrutura essencialmente fabril, pautada pela rigidez e controle do tempo, não consegue proporcionar esse tempo de elaboração literária, cabe a ela, no entanto, despertar os educandos para a existência desse tempo. A escola deve descortinar outros ritmos de tempo, dar ciência aos educandos de que ele existe e pode ser, não só prazeroso como transformador. Devemos levar em consideração também que a reelaboração de cada leitura constrói um caminho, uma trajetória.

TRV - A gente leu, claro, todo mundo já tinha lido, mas a gente leu publicamente O homem e o cavalo, A morta; a gente fazia as leituras disso.

$\mathrm{MH}$ - Públicas?

TRV - Públicas. Não ia ninguém, mas eram públicas. A do O homem e o cavalo não foi ninguém. Acho que foi o Lucas (diretor musical) e a única foto que tem de registro do Lucas na leitura, ele está dormindo. (Entrevista com Thiago Reis Vasconcelos - 14/02/2012). 
No teatro, essa leitura também sofre as intempéries do ritmo do trabalho, da sobrevivência. No entanto, ali esse tempo é constantemente "cavado", buscado e almejado juntamente com as demais práticas teatrais. As leituras em grupo ocasionam reelaborações após sua escuta e não só durante a sua realização. Em casa, nos empregos, diante de situações que remetam a situações e contextos lidos (e, em geral, debatidos), o referencial será acionado e confrontado com a realidade. Esses desdobramentos tem um caráter essencialmente formativo, pois convocam o sujeito a ler e pensar constantemente o que o cerca. E isso numa chave poética, pois seu olhar e sua escuta estão treinados, sua percepção está aguda. O treino confere-Ihe não só perspicácia para enxergar nas entrelinhas do cotidiano, como para inferir-lhe e apropriar-se de seus elementos para, no teatro, utilizá-los como matéria-prima para a criação.

Não podemos deixar de mencionar o tempo dispendido para os ensaios e práticas dos grupos. Na Cia. Paidéia, com a Paideia Jovem, há dias inteiros de ensaios, leituras, aulas de canto, filmes e recepção de outros grupos que apresentam no espaço. Na Cia. Antropofágica, com o PY, são doze horas sequenciais (virada da madrugada) de imersão envolvendo leitura, improvisos, exercícios cênicos, atuação, jantar. Esse tempo, apesar das implicações negativas (o cansaço é a principal delas), é de uma complexidade que talvez não consigamos abordar corretamente. A leitura feita dessa forma, sem pressa para ocorrer, alternada (ou sustentada) por música, compartilhamento, cenas, atividade corporal, jogos teatrais etc. rompe com o tempo pautado pela lógica do trabalho, do rotineiro ${ }^{5}$. É um tempo de duração (durée) como o referido pela psicanalista Maria Rita Kehl, em estudo sobre as depressões e a relação dos depressivos com o tempo:

(...) a durée guarda algum parentesco com o sentimento de continuidade da existência (...). Tal sentimento é tributário tanto de repetições prazerosas de rituais de conforto e amparo fornecidos pelo meio familiar quanto das temporalidades distendidas que a própria criança descobre, ou inventa sozinha: longos períodos

\footnotetext{
5 "Por volta das 3h30, o sono era devastador, mas a maior parte permanecia no firme propósito de estudar o Manifesto. O ritmo era lento, difícil, mas possível. A cada trecho lido coletivamente, pausas para o entendimento, para destacar os trechos mais importantes e, embora não fosse o intuito, refletir sobre os desdobramentos daqueles conceitos e ideias na contemporaneidade. (...) Fui embora após a discussão do texto (6h30), mas o grupo ainda permaneceu no espaço". (Relatório de observação / Antropofágica - 18/11/11)
} 
roubados ao tempo dos relógios, nos quais a criança se dedica às atividades criativas da brincadeira e do devaneio. (Kehl, 2009: 142)

Apesar da quantidade de horas, das regras e das tarefas a serem desempenhadas, os integrantes permanecem. O cansaço é já faz parte do contexto, é tolerado e até previsto. Dormir em meio às leituras, divagar, deitar, sair e voltar são ações comuns e não geram sequer comentários. Quando um dos integrantes, responsável pelas falas de um personagem, cochila durante a leitura, automaticamente outro o substitui. Essas fugas ou escapes também ocorrem na esfera escolar. No entanto, a tolerância lá é menor, mesmo quando se tem ciência de que o cansaço é proveniente da dupla trabalho-estudo por parte do aluno. Esse respeito pelo cansaço, talvez já esperado na longa jornada noite adentro, revela, no entanto, uma descontração com relação aos procedimentos de leitura e encenação. Uma descontração, não um descompromisso. Essa descontração imprime traços peculiares - mais livres, menos "respeitosos" - na maneira de lidar com o texto, com a leitura do texto no espaço físico, no tempo, no corpo. Uma vez que escolheram estar ali para a partilha de leitura e de cena, ao corpo é conferida relativa liberdade. $O$ oposto ocorre na escola: como os alunos, majoritariamente, não querem (ou não compreendem) porque estão ali, o controle sobre os corpos precisa ser constante, uma vez que o intuito, a finalidade das atividades propostas - entre elas, a leitura - não está clara para os envolvidos.

Existe ainda o tempo da fala, o ritmo do texto e o da cena. $O$ texto lido, em especial o texto dramático, aponta para exigências no trato com as especificidades da leitura oral. Além da entonação das expressões e das palavras, da prosódia, da partitura do texto, há o ritmo das falas e o ritmo da cena. O ritmo apresenta implicações nas leituras realizadas. Pelas entonações e pelo ritmo, por exemplo, é possível distinguir quando uma leitura é apenas exploratória, ou quando é "pra valer", quando já se comporta como leitura cênica. Outra questão que imprime traços às leituras teatrais é a exaustão. Fazer, fazer, fazer, ensaiar até a exaustão. Isso também é um princípio que deve ser mencionado e pensado; esse traço desperta outro tipo de relação com o texto: a repetição desencadeia maior in- 
timidade, apropriação quase física, diferente da leitura individual e silenciosa. Diferente, mas em diálogo com ela, impulsionando-a, inclusive ${ }^{6}$.

\section{Considerações finais}

A leitura coletiva, assim como os demais elementos mobilizados no teatro, aparece como possibilidade de fomentar o treino do olhar e da escuta, além de fundar um espaço simbólico para que isso ocorra. Os artistas, pelo contato permanente com diferentes processos e resultantes artísticas, por enxergarem uma finalidade na leitura, tornam mais aguda sua percepção e recepção. Com algum empenho e incentivo, os elementos presentes nas leituras coletivas teatrais poderiam fertilizar também as leituras escolares.

$6 \mathrm{MH}$ - E essas leituras do grupo? Essas leituras de sexta-feira, em que se vira a noite?...

M- (...) A gente leu Liberdade (Liberdade, liberdade), o Zumbi (Arena conta Zumbi), Auto dos 99\%, que eu adoro. Teve do Plínio Marcos, Abajur Lilás, Homens de papel... (...) Quando as máquinas param...

$\mathrm{MH}$ - Você leu todos?

$\mathrm{M}$ - A gente leu aqui, todos juntos.

$\mathrm{MH}$ - E o que você acha dessas leituras coletivas?

$\mathrm{M}$ - Eu gosto. Eu acho que fica mais interessante do que eu ler em casa sozinho.

$\mathrm{MH}$ - Mas Harry Potter...

M - Harry Potter é legal ler sozinho... (...) Até porque com o pessoal, com o Thiago (diretor), eu entendo mais. Não sei, eu consigo pegar mais os personagens. Que nem, eu comecei a ler o ... a gente começou a ler o Auto dos 99\% aqui; eu gostei tanto que eu fui atrás e eu li várias vezes em casa depois. Sozinho. (Entrevista com M., integrante do PY [Cia. Antropofágica], em 17/04/2012). 


\section{Referências}

BOURDIEU, Pierre. “O campo intelectual: um mundo à parte”. In: Coisas Ditas. São Paulo: Brasiliense, 1990.

CERVANTES, Miguel de. Dom Quixote de la Mancha. São Paulo: Abril Cultural, 1981.

CANDIDO, Antonio. "O direito à literatura". In: Vários escritos. Rio de Janeiro: Ouro sobre Azul, 2013.

EAGLETON, Terry. Teoria da Literatura: uma introdução. São Paulo: Martins Fontes, 2006. FISH, Stanley. "Interpreting the Variorum". In: FISH, S. Is there a text in this class? : The authority of interpretive communities. Cambridge, Mass: Harvard University Press, 1980.

ISER, Wolfgang. “O jogo do texto". In: LIMA, L. C. (Org.) A literatura e o leitor. Rio de Janeiro: Paz e Terra, 2002.

JAUSS, H. R. "O prazer estético e as experiências fundamentais da poiesis, aisthesis e khatarsis". In: LIMA, L. C.(Org.) A literatura e o leitor. Rio de Janeiro: Paz e Terra, 2002. JOUVE, Vincent. A leitura. São Paulo: Editora UNESP, 2002.

KEHL, Maria Rita. O tempo e o cão: a atualidade das depressões. São Paulo: Boitempo, 2009.

MANGUEL, Alberto. Uma história da leitura. São Paulo: Companhia das Letras, 1997.

PROUST, Marcel. Sobre a leitura. (Trad. Carlos Vogt). Campinas (SP): Pontes, 2011.

ZUMTHOR, Paul. Performance, recepção, leitura. São Paulo: Cosac Naify, 2007. 